AJChE 2017, Vol. 17, No. 2, $106-113$

\title{
Process Optimization of Carbon Dioxide Adsorption using Nitrogen-Functionalized Graphene Oxide via Response Surface Methodology Approach
}

Fritzie Hannah B. Baldovino ${ }^{1}$

Nathaniel P. Dugos *,1

Susan A. Roces ${ }^{1}$

Armando T. Quitain ${ }^{2}$

Tetsuya Kida ${ }^{2}$

${ }^{1}$ Chemical Engineering Department, Gokongwei College of Engineering, De La Salle University, 2401 Taft Avenue, 0922 Manila, Philippines

${ }^{2}$ Graduate School of Science and Technology, Kumamoto University, 2-39-1 Kurokami, Chuo-ku, Kumamoto 860-8555, Japan

*e-mail: nathaniel.dugos@dlsu.edu.ph

This paper presents a response surface methodology approach in the optimization of the carbon dioxide temperature-programmed adsorption process using a new material referred as nitrogen-functionalized graphene oxide. This material was synthesized by loading nitrogen groups to graphene oxide using aqueous ammonia in supercritical condition. Later on, it was utilized as a sorbent for carbon dioxide adsorption. This process was optimized by implementing a response surface methodology coupled with a BoxBehnken design for the effects of three factors: adsorption temperature, carbon dioxide flow rate, and the amount of adsorbent. In analyzing the response surface, a model equation was generated based on the experimental data by regression analysis. This model equation was then utilized to predict optimum values of response. Furthermore, response optimizer was also conducted in identifying factor combination settings that jointly optimize the best response.

Keywords : carbon dioxide adsorption; graphene oxide; functionalization; ammonia; response surface methodology, nitrogen-functionalized graphene oxide

\section{INTRODUCTION}

The accumulation of carbon dioxide $\left(\mathrm{CO}_{2}\right)$ in the atmosphere is considered to be a major environmental hazard. $\mathrm{CO}_{2}$ concentrations in the atmosphere has increased by $40 \%$ since pre-industrial times (IEA, 2015). In this regard, studies were conducted to develop a stable, safe, and environmentally acceptable method for $\mathrm{CO}_{2}$ capture and storage emissions. Among numerous technologies available for $\mathrm{CO}_{2}$ capture, adsorption using solid adsorbent were preferred to address 
existing drawbacks of other technologies. The advantages of this technology are its adsorbents were relatively thermally stable, corrosion resistant, with high loading capacities, and with tunable surfaces (Sayari et al. 2011, Lu et al. 2014). This method is continuously developed by evaluating other possible solid adsorbents to increase $\mathrm{CO}_{2}$ adsorption capacity such as incorporating amine-based functional groups to mimic a solid amine-based sorbent (Serna- Guerrero et al. 2010). Meanwhile, aqueous ammonia $\left(\mathrm{NH}_{3} \mathrm{aq}\right)$ was one of the promising liquid solvents that were previously studied using absorption process (Diao et al. 2004, Jilvero et al. 2014). The use of this in $\mathrm{CO}_{2}$ capture was not yet commercialized due to problems such as volatilization, thermally unstable, and causes corrosion (Zhao et al. 2012). In this regard, the use of $\mathrm{NH}_{3}$ aq was further explored in adsorption process as a source of $\mathrm{N}$-group and was loaded into a graphene oxide (GO). The new material referred as nitrogen-functionalized graphene oxide (N-FGO) were characterized and evaluated for $\mathrm{CO}_{2}$ adsorption. Details of functionalization and characterization results were reported in another paper (Baldovino et al. 2016). It was observed that this material is thermally stable, does not volatilize and is corrosion resistant. The main objective of this study is to optimize the operating parameters involved in $\mathrm{CO}_{2}$ adsorption processes such as temperature $\left({ }^{0} \mathrm{C}\right), \mathrm{CO}_{2}$ flow rate $(\mathrm{ml} / \mathrm{min})$, and the amount of adsorbent (mg). Response surface methodology (RSM) coupled with Box-Behnken design (BBD) was utilized.

\section{METHODS}

\section{Nitrogen-Functionalization of Graphene Oxide}

As-prepared GO (a detailed process discussed in Baldovino et al. 2016) was functionalized with $\mathrm{N}$-groups via supercritical (SC) conditions. GO was combined with $\mathrm{NH}_{3}$ aq in a batch reactor and was subjected to supercritical conditions $\left(300^{\circ} \mathrm{C}\right.$ and $40 \mathrm{MPa}$ as the critical temperature and pressure of $\mathrm{NH}_{3}$, respectively) inside a furnace. The detailed functionalization method was reported elsewhere (Baldovino et al. 2016). Thereafter, it was filtered and then dried in an oven at $60^{\circ} \mathrm{C}$ for $24 \mathrm{~h}$. The resulting material referred to as $\mathrm{N}-\mathrm{FGO}$ were then tested in $\mathrm{CO}_{2}$ adsorption process as a sorbent.

\section{Carbon Dioxide Adsorption Measurements}

The $\mathrm{CO}_{2}$ temperature-programmed adsorption (TPA) performance of the $\mathrm{N}$ FGO was evaluated in a modified setup of TG/DTA 6300 at atmospheric pressure. A certain amount of an adsorbent was placed in a small aluminum pan and was loaded inside the TGA. First, it was heated at $120^{\circ} \mathrm{C}$ for $30 \mathrm{~min}$ to remove moisture content. The analysis adsorption temperature was then set with a continuous flow of $\mathrm{N}_{2}$ gas until the system was stable. $\mathrm{N}_{2}$ gas was then turned OFF and pure $\mathrm{CO}_{2}$ gas was flowed into the system for $180 \mathrm{~min}$ to achieve complete saturation. The weight increase after the adsorption process was referred to as the adsorption capacity of the adsorbent. 


\section{Design of Experiment and Statistical}

\section{Analysis}

The $\mathrm{CO}_{2}$ TPA process using N-FGO were optimized and evaluated using RSM-BBD. Statistical software, MINITAB 14 and JMP, were used to generate experimental designs, statistical analyses, and regression models. A quadratic polynomial equation was used to predict the dependent variables (responses) as a function of independent variables (factors) and their interactions (see Equation 1).

$$
\begin{aligned}
y= & b_{0}+b_{1} x_{1}+b_{2} x_{2}+b_{3} x_{3} \\
& +b_{11} x_{1}^{2}+b_{22} x_{2}^{2}+b_{33} x_{3}^{2} \\
& +b_{12} x_{1} x_{2}+b_{13} x_{1} x_{3}+b_{23} x_{2} x_{3}
\end{aligned}
$$

To interpret the regression coefficients for curvilinear relationships and interaction terms, a response surface regression was used to develop the model equation. Analysis of variance (ANOVA) was applied to determine the goodness of fit of the model, main effects and interactions between factors and response(s). The goodness of fit can be evaluated through the coefficients of determination, $R^{2}$, and $R^{2}$ adj. This is used to summarize the difference between observed values and values expected under the model in question. The higher the value of $R^{2}$ and $R^{2} a d j$ indicates that the model explains all the variability of the response data around its mean (Körbahti et al. 2008).

Thereafter, insignificant factors were eliminated depending on P-value. P-value lower than 0.05 indicates that the factor is statistically significant based on 95\% confidence interval (Choi et al. 2014). Lastly, the final model based on Equation 1 was obtained.

\section{RESULTS AND DISCUSSIONS}

\section{Statistical Analysis on Temperature Programmed $\mathrm{CO}_{2}$ Adsorption}

An experimental design was prepared based on factors and levels listed in Table 1. Factors include: temperature $\left(x_{1},{ }^{\circ} \mathrm{C}\right), \mathrm{CO}_{2}$ flowrate $\left(x_{2}, \mathrm{ml} / \mathrm{min}\right)$, and amount of adsorbent $\left(x_{3}, \mathrm{mg}\right)$. The levels of each factor were designated by coded units using $-1,0$ and 1 that pertains for low, middle and high values, respectively.

Table 1. Generation of 3-factor, 3-level response surface design

\begin{tabular}{lccc}
\multicolumn{1}{c}{ Factors } & \multicolumn{3}{c}{ Levels } \\
\cline { 2 - 5 } & $\mathbf{- 1}$ & $\mathbf{0}$ & $\mathbf{1}$ \\
\hline$x_{1}:$ Temperature $\left({ }^{0} \mathrm{C}\right)$ & 40 & 80 & 120 \\
$x_{2}: \quad \mathrm{CO}_{2} \quad$ flowrate & 100 & 200 & 300 \\
$(\mathrm{~mL} / \mathrm{min})$ & & & \\
$\begin{array}{l}x_{3}: \text { Amount of adsorbent } \\
(\mathrm{mg})\end{array}$ & 4 & 6 & 8 \\
\hline
\end{tabular}

These variables and their respective values were chosen based on results of preliminary runs conducted and from the existing limitations of the set-up utilized in the $\mathrm{CO}_{2}$ TPA. In detail, lower and upper values of adsorption temperature were chosen as $40^{\circ} \mathrm{C}$ and $120^{\circ} \mathrm{C}$, since no or less adsorption will occur at temperatures lower than $40^{\circ} \mathrm{C}$ and greater than $120^{\circ} \mathrm{C}$. Likewise, low adsorption occurs at values lower than $100 \mathrm{ml} / \mathrm{min}$ and greater than $300 \mathrm{ml} / \mathrm{min}$ of $\mathrm{CO}_{2}$ flowing. Also, less adsorption occurred at values lower than $4 \mathrm{mg}$ of adsorbent. Moreover, the sample holder can only accommodate around 8mg of the sample.

Using RSM-BBD, an experimental design layout with 15 runs was generated (see Table 2). The experimental runs were in a randomized order to minimize the effects 
Table 2. Experimental design layout and experimental results of response

\begin{tabular}{|c|c|c|c|c|c|c|c|}
\hline \multirow{2}{*}{$\begin{array}{l}\text { Run } \\
\text { No. }\end{array}$} & \multicolumn{3}{|c|}{ Coded variables } & \multicolumn{3}{|c|}{ Actual variables } & \multirow{2}{*}{$\frac{\text { Response }}{Y}$} \\
\hline & $x_{1}$ & $x_{2}$ & $x_{3}$ & $x_{1}$ & $x_{2}$ & $x_{3}$ & \\
\hline 1 & 0 & 1 & -1 & 80 & 300 & 4 & 0.002 \\
\hline 2 & 1 & 1 & 0 & 120 & 300 & 6 & 0.0009 \\
\hline 3 & -1 & 0 & 1 & 40 & 200 & 8 & 0.00272 \\
\hline 4 & 0 & -1 & 1 & 80 & 300 & 8 & 0.006 \\
\hline 5 & 0 & 0 & 0 & 80 & 200 & 6 & 0.00084 \\
\hline 6 & -1 & 1 & 0 & 40 & 300 & 6 & 0.00126 \\
\hline 7 & -1 & 0 & -1 & 40 & 200 & 4 & 0.0004 \\
\hline 8 & 0 & -1 & 1 & 80 & 100 & 8 & 0.00688 \\
\hline 9 & -1 & -1 & 0 & 40 & 100 & 6 & 0.00186 \\
\hline 10 & 0 & -1 & -1 & 80 & 100 & 4 & 0.00296 \\
\hline 11 & 1 & 0 & -1 & 120 & 200 & 4 & 0.00024 \\
\hline 12 & 0 & 0 & 0 & 80 & 200 & 6 & 0.00072 \\
\hline 13 & 0 & 0 & 0 & 80 & 200 & 6 & 0.00114 \\
\hline 14 & 1 & 0 & 1 & 120 & 200 & 8 & 0.00288 \\
\hline 15 & 1 & -1 & 0 & 120 & 100 & 6 & 0.00084 \\
\hline
\end{tabular}

Table 3. Estimated regression coefficients and ANOVA for $\mathrm{CO}_{2}$ TPA

\begin{tabular}{|c|c|c|c|c|c|c|}
\hline Source** & $\begin{array}{l}\text { Sum of } \\
\text { squares }\end{array}$ & $\begin{array}{l}\text { Degrees of } \\
\text { freedom }\end{array}$ & $\begin{array}{l}\text { Mean } \\
\text { square }\end{array}$ & F-value & p-value & Result \\
\hline Model & $5.27 e-6$ & 9 & $5.85 \mathrm{e}-7$ & 17.8782 & 0.042 & significant \\
\hline$x_{1}$ & $2.4 \mathrm{e}-7$ & 1 & $2.4 \mathrm{e}-7$ & 0.7266 & 0.433 & not significant \\
\hline$x_{2}$ & $7.1 \mathrm{e}-7$ & 1 & $7.1 \mathrm{e}-7$ & 2.1612 & 0.201 & not significant \\
\hline$x_{3}$ & $2.07 e-5$ & 1 & $2.07 e-5$ & 63.2953 & 0.001 & significant \\
\hline$x_{1}{ }^{*} x_{2}$ & $1.1 \mathrm{e}-7$ & 1 & $1.1 \mathrm{e}-7$ & 0.3324 & 0.589 & not significant \\
\hline$x_{1}^{*} x_{3}$ & $2.56 \mathrm{e}-8$ & 1 & $2.56 \mathrm{e}-8$ & 0.0781 & 0.791 & not significant \\
\hline$x_{2}^{*} x_{3}$ & $1.6 e-9$ & 1 & $1.6 e-9$ & 0.0049 & 0.947 & not significant \\
\hline$x_{1}^{*} x_{1}$ & $6.17 \mathrm{e}-6$ & 1 & $6.17 \mathrm{e}-6$ & 18.8273 & 0.007 & significant \\
\hline$x_{2}^{*} x_{2}$ & $9.54 \mathrm{e}-6$ & 1 & $9.54 \mathrm{e}-6$ & 29.1226 & 0.003 & significant \\
\hline$x_{3}{ }^{*} x_{3}$ & $1.41 \mathrm{e}-5$ & 1 & $1.41 \mathrm{e}-5$ & 42.9645 & 0.001 & significant \\
\hline Residual & $1.6381 \mathrm{e}-6$ & 5 & $3.27 \mathrm{e}-7$ & - & - & \\
\hline Lack of fit & $1.5445 \mathrm{e}-6$ & 3 & $5.13 e-7$ & 11.0007 & 0.0845 & not significant \\
\hline Pure error & $9.36 \mathrm{e}-8$ & 2 & $4.68 \mathrm{e}-8$ & - & - & \\
\hline \multicolumn{7}{|c|}{$R^{2}(0.9700)$ and $R^{2}$ adjusted $(0.9160)$} \\
\hline
\end{tabular}

${ }^{* *} x_{1:}$ temperature, $x_{2}: \mathrm{CO}_{2}$ flow rate, $x_{3:}$ amount of adsorbent

of the uncontrolled factors. After $\mathrm{CO}_{2}$ TPA, the response $\left(Y\right.$ ) amount of $\mathrm{CO}_{2}$ adsorbed $\left(\mathrm{mmol} \mathrm{CO}_{2}\right)$ were recorded in the same table. From the results, the range of response was observed from 0.00024 to $0.00688 \mathrm{mmol} \mathrm{CO}_{2}$.

An analysis of variance (ANOVA) was conducted to analyze the fitness of model and the interactions between the variables and response (See Table 3). The goodness of fit of the polynomial model was determined by the high value of the coefficient of determination, $R^{2}(0.97)$ and $R^{2}$ adjusted (0.9160). Significant factors along with the constant were identified as the following: $x_{3}, x_{1}{ }^{2}, x_{2}{ }^{2}$, and $x_{3}{ }^{2}$. The final model equation using coded units after eliminating the insignificant factors is 
110 Process Optimization of Carbon Dioxide Adsorption using Nitrogen-Functionalized Graphene Oxide via Response Surface Methodology Approach

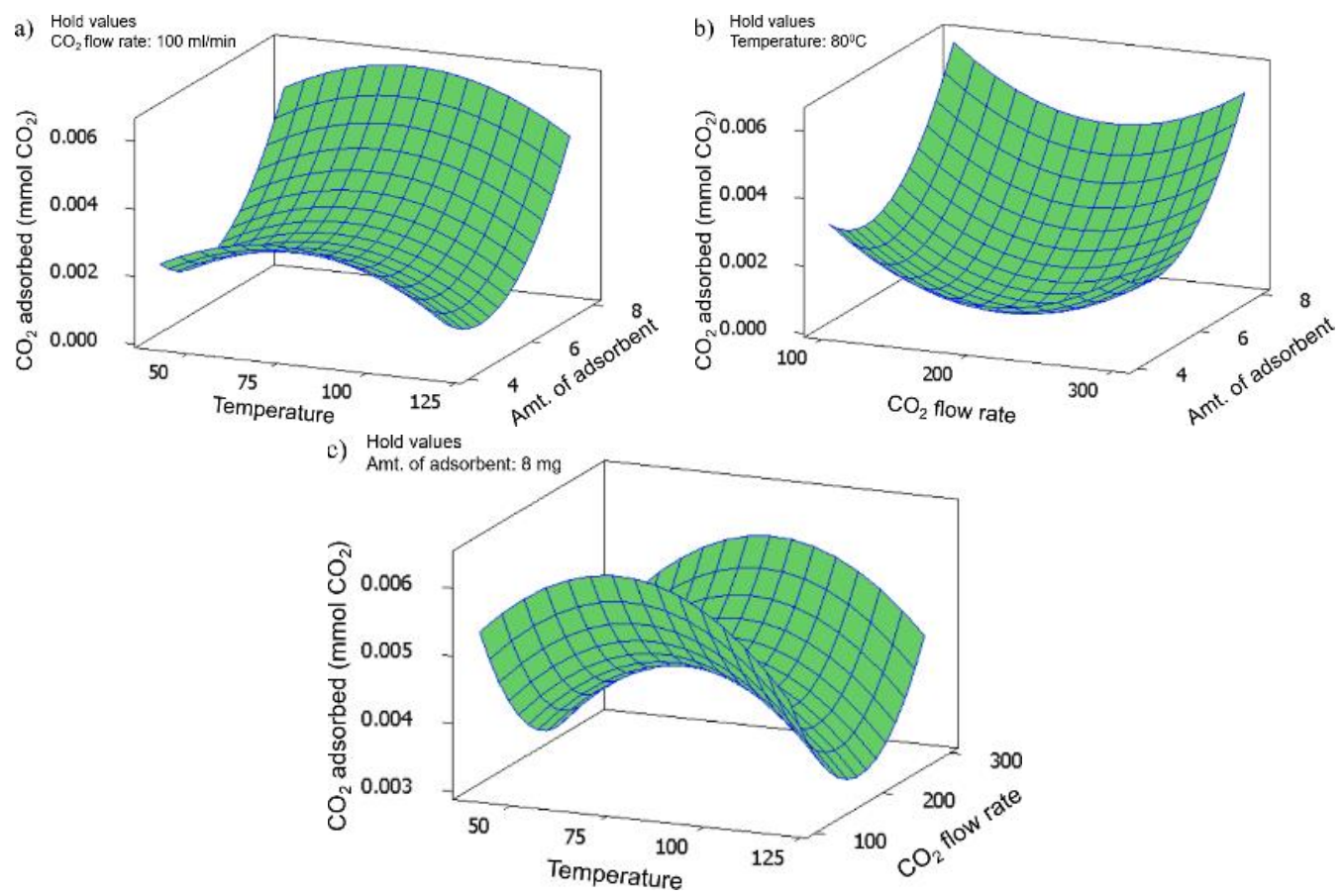

Fig. 1: Wireframe surface plots for (a) temperature and amt. of adsorbent, (b) $\mathrm{CO}_{2}$ flow rate and amt. of adsorbent, and (c) temperature and $\mathrm{CO}_{2}$ flow rate.

reported in Eq. 2.

$$
\begin{aligned}
y= & 0.000900+0.00161 x_{3} \\
& -0.001292 x_{1}^{2}+0.0016808 x_{2}^{2} \\
& +0.001953 x_{3}^{2}
\end{aligned}
$$

This model equation based form coded units can predict the response by inputting different values for each factor as well as determining the optimal response. Thus, optimized parameters and response are reported in Table 4.

Table 4. Optimized Conditions for $\mathrm{CO}_{2}$ TPA

\begin{tabular}{lc}
\hline \multicolumn{1}{c}{ Parameter } & Values \\
\hline$x_{1}:$ Temperature & $80^{\circ} \mathrm{C}$ \\
$x_{2}: \mathrm{CO}_{2}$ Flowrate & $100 \mathrm{~mL} / \mathrm{min}$ \\
$x_{3}:$ Amount of adsorbent & $8 \mathrm{mg}$ \\
$Y$ (predicted value) & $0.0063 \mathrm{mmol} \mathrm{CO} 2$ \\
\hline
\end{tabular}

A comparison of 3D wireframe surface plots was prepared to further visualize the relationship between factors. Predictor factors are represented by the $x$ - and $y$-axis and the response are displayed on the $z$ axis. One factor is fixed as two variables are investigated as shown in the plots in Figure 1.

\section{Analysis of The Optimum $\mathrm{CO}_{2}$ TPA Conditions}

The optimized response is equal to $0.0063 \mathrm{mmol} \mathrm{CO}_{2}$ when factors are set to $80^{\circ} \mathrm{C}, 100 \mathrm{ml} / \mathrm{min}$, and $8 \mathrm{mg}$ of adsorbent. An optimum temperature of $80^{\circ} \mathrm{C}$ is relatively higher than the usual temperature of $25^{\circ} \mathrm{C}$ in other $\mathrm{CO}_{2}$ adsorption studies utilizing other sorbents. This will be an advantage if applied to actual post-combustion $\mathrm{CO}_{2}$ capture by the reduction of energy required to cool down the gases before adsorption.

By evaluating the kinetics of the TPA process, $\mathrm{CO}_{2}$ adsorption mechanism using $\mathrm{N}-\mathrm{FGO}$ was found to follow a combination of physical (physisorption) and chemical 
(chemisorption) interaction between the $\mathrm{N}$ FGO and the $\mathrm{CO}_{2}$ (Baldovino, 2017, De La Salle University, Ph. D. Thesis). At low temperature, adsorption followed physisorption. When the temperature was increased, most of the interactions found in the $\mathrm{CO}_{2}$ adsorption were governed by chemisorption. At $80^{\circ} \mathrm{C}$ is just appropriate to allow both physisorption and chemisorption between the N-FGO and $\mathrm{CO}_{2}$. On the other hand, the optimum value of flowrate is $100 \mathrm{ml} / \mathrm{min}$. If the values for flow rate were changed in the response optimizer to 200 or $300 \mathrm{ml} / \mathrm{min}$, response values were lower. This is due to the system inside the TGA set-up used in the adsorption was continuous. When gases enter the system, it will also go out of the vent continuously. Therefore, the faster the flow rate the faster it will go out of the system leaving less time to react with the sorbent. Meanwhile, $8 \mathrm{mg}$ of adsorbent is necessary to attain an optimum response. When the amount was set to lower than this, the response was also lower. The higher the surface area exposed the higher the adsorbed $\mathrm{CO}_{2}$. The sample sorbent holder is also important. The holder is made of a circular pan with a size just enough to contain around $7 \mathrm{mg}$ of sample. When $8 \mathrm{mg}$ of samples was used, it exceeded the capacity of the holder, therefore, creating a mountain or pile of samples on top. Thus, providing more surface area to react with the $\mathrm{CO}_{2}$. Unlike when the amount of sorbent is lower, it is just enough to fill in the holder fixing the surface area available for reacting.

\section{Reproducibility Runs Prepared Under Optional Conditions}

To evaluate the reproducibility and accuracy of the model and the optimal conditions predicted, three confirmations runs were conducted. The average values of these repeated runs were reported and compared with the predicted value in Table

5. As can be seen, the experimental results were not significantly different with the predicted value as indicated by the deviation error. The close agreement between the experimental and the predicted value suggest that the developed model can correlate the $\mathrm{CO}_{2}$ TPA factors/parameters to $\mathrm{CO}_{2}$ adsorption with a high degree of accuracy.

Table 5. Predicted a experimental values of the studied response obtained at optimum condition

\begin{tabular}{cccc}
\hline Response & $\begin{array}{c}\text { Experimental } \\
\text { results* }\end{array}$ & $\begin{array}{c}\text { Predicted } \\
\text { value }\end{array}$ & $\begin{array}{c}\text { Error } \\
\text { (\%) }\end{array}$ \\
\hline $\begin{array}{c}\mathrm{CO}_{2} \\
\text { adsorption } \\
\text { capacity } \\
(\mathrm{mmol} \\
\left.\mathrm{CO}_{2}\right)\end{array}$ & 0.0062 & 0.0063 & $1.59 \%$ \\
\hline
\end{tabular}

* Represents the average values of the repeated experiments

\section{CONCLUSION}

The temperature-programmed $\mathrm{CO}_{2}$ adsorption using $\mathrm{N}-\mathrm{FGO}$ was optimized by response surface methodology with BoxBehnken design (RSM-BBD). Optimal values of the response (amount of $\mathrm{CO}_{2}$ 
112 Process Optimization of Carbon Dioxide Adsorption using Nitrogen-Functionalized Graphene Oxide via Response Surface Methodology Approach

adsorbed: $0.0063 \mathrm{mmol} \quad \mathrm{CO}_{2} / 8 \mathrm{mg}$ adsorbent) and factors (temperature: $80^{\circ} \mathrm{C}$, $\mathrm{CO}_{2}$ flow rate: $100 \mathrm{ml} / \mathrm{min}$, and the amount of adsorbent: $8 \mathrm{mg}$ ) were also determined based on the RSM-BBD. A model equation was generated to predict the amount of the $\mathrm{CO}_{2}$ adsorbed at any values of temperature, $\mathrm{CO}_{2}$ flow rate, and the amount of adsorbent used. This model will be useful as a basis for future similar studies to predict values of factors and responses to further improve the process.

\section{ACKNOWLEDGEMENT}

The authors would like to thank the Engineering Research and Development for Technology (ERDT) for the research funding and dissemination support.

\section{REFERENCES}

1. Baldovino, F. H. B., Quitain, A. T., Dugos, N. P., Roces, S. A., Koinuma, M., Yuasa, M., \& Kida, T. (2016). Synthesis and characterization of nitrogenfunctionalized graphene oxide in hightemperature and high-pressure ammonia. RSC Adv, 6, 113924-113932. doi:10.1039/c6ra22885b.

2. Baldovino, F. H. B., Quitain, A. T., Dugos, N. P., Roces, S. A., Koinuma, M., Yuasa, M., \& Kida, T. (2017). Synthesis and characterization of nitrogenfunctionalized graphene oxide in hightemperature and high-pressure ammonia. RSC Adv., 7, 3852. doi:10.1039/c6ra90131j.

3. Baldovino, F. H. B., Quitain, A. T., Dugos, N. P., and Roces, S. A. (2017). Ammonia surface-functionalized nanomaterials for carbon dioxide capture. De La Salle University. Ph.D. Thesis.

4. Choi, A. E., Roces, S., Dugos, N., Futalan, C. M., Lin, S., \& Wan, M. (2014). Optimization of ultrasound-assisted oxidative desulfurization of model sulfur compounds using commercial ferrate (VI). Journal of the Taiwan Institute of Chemical Engineers, 45(6), 2935-2942.

doi:10.1016/j.jtice.2014.08.003.

5. Diao, Y., Zheng, X., He, B., Chen, C., \& $\mathrm{Xu}, \mathrm{X}$. (2004). Experimental study on capturing $\mathrm{CO}_{2}$ greenhouse gas by ammonia scrubbing. Energy Conversion and Management, 45(1314), 2283-2296. doi:10.1016/j.enconman.2003.10.011.

6. Jilvero, H., Mathisen, A., Eldrup, N., Normann, F., Johnsson, F., Müller, G. I., \& Melaaen, M. C. (2014). Technoeconomic Analysis of Carbon Capture at an Aluminum Production Plant Comparison of Post-combustion Capture Using MEA and Ammonia. Energy Procedia, 63, 6590-6601. doi:10.1016/j.egypro.2014.11.695.

7. Körbahti, B. K., \& Rauf, M. (2008). Response surface methodology (RSM) analysis of photoinduced decoloration of toludine blue. Chemical Engineering Journal, 136(1), 25-30. doi:10.1016/j.cej.2007.03.007.

8. Lu, A., Hao, G., \& Zhang, X. (2014). Porous Carbons for Carbon Dioxide Capture. Green Chemistry and Sustainable Technology, 15-77.

9. Sayari, A., Belmabkhout, Y., \& SernaGuerrero, R. (2011). Flue gas treatment via $\mathrm{CO}_{2}$ adsorption. Chemical Engineering Journal, 171(3), 760-774. 
Fritzie Hannah B. Baldovino, Nathaniel P. Dugos, Susan A. Roces, Armando T. Quitain, and

Tetsuya Kida

10. Serna-Guerrero, R., Belmabkhout, Y., \& Sayari, A. (2010). Modeling $\mathrm{CO}_{2}$ adsorption on amine-functionalized mesoporous silica: 1. A semi-empirical equilibrium model. Chemical Engineering Journal, 161(1-2), 173-181. doi:10.1016/j.cej.2010.04.024.
11. Zhao, B., Su, Y., Tao, W., Li, L., \& Peng, Y. (2012). Post-combustion $\mathrm{CO}_{2}$ capture by aqueous ammonia: A state-of-theart review. International Journal of Greenhouse Gas Control, 9, 355-371. doi:10.1016/j.ijggc.2012.05.006. 